(2) Open Access Full Text Article

\title{
Measurement of central corneal thickness by ultrasonic pachymeter and oculus pentacam in patients with well-controlled glaucoma: hospital- based comparative study
}

\author{
This article was published in the following Dove Press journal: \\ Clinical Ophthalmology \\ I March 2016 \\ Number of times this article has been viewed
}

\section{Riyam Faihan Rashid \\ Qasim K Farhood \\ Department of Ophthalmology, College of Medicine, University of Babylon, Babylon, Iraq}

Correspondence: Qasim K Farhood Department of Ophthalmology, College of Medicine, University of Babylon, Babylon 5200I, Iraq

Tel +964 780 I I 79098

Email qasim_1964@ymail.com
Background: The measurement of central corneal thickness (CCT) plays an important role in the diagnosis and treatment of glaucoma and many corneal diseases.

Objective of the study: To compare the measurement of CCT by ultrasonic pachymeter with that measured by oculus pentacam in both normal subjects and patients with well-controlled glaucoma.

Patients and methods: In 173 eyes of both controls and patients with open-angle glaucoma (normal intraocular pressure) attending Ibn Al Haitham Teaching Eye Hospital, CCT was measured by oculus pentacam and then by ultrasound pachymeter at the same morning by the same technicians.

Results: The results showed no significant difference in CCT readings measured by the two devices in both glaucoma and control groups (glaucoma group: $547.29 \pm 49.32 \mu \mathrm{m}$ with pentacam vs $547.66 \pm 45.24 \mu \mathrm{m}$ with ultrasound pachymeter; control group: $551.02 \pm 36.28 \mu \mathrm{m}$ with pentacam vs $541.25 \pm 34.96 \mu \mathrm{m}$ with ultrasound pachymeter). $P$-values were $>0.05$ in both groups (statistically not significant).

Conclusion and recommendation: Ultrasonic pachymeter and oculus pentacam can be used interchangeably in measuring CCT, and we recommend a nontouch method (in this study, pentacam Scheimpflug camera) for measuring CCT during assessment of patients with glaucoma or any ocular disease or surgery.

Keywords: CCT, open-angle glaucoma, ultrasound pachymeter, Scheimpflug camera

\section{Introduction}

The cornea is a transparent, avascular tissue; its diameter measures 11-12 mm horizontally and $10-11 \mathrm{~mm}$ vertically. Its refractive index is 1.376 . The cornea is aspheric, although its radius of curvature is often recorded as a spherocylindrical convex mirror representing the central anterior corneal surface, also called the corneal cap. ${ }^{1}$

The cornea is the principal refractive surface of human eye and along with sclera forms the outermost coat of the eyeball. ${ }^{2}$

The precorneal tear film consists of: "outer lipid" layer, which is secreted by the meibomian glands ( $0.1 \mu \mathrm{m}$ thick); "intermediate aqueous" layer, which is secreted by the lacrimal glands ( $7 \mu \mathrm{m}$ thick); “inner mucous" layer secreted by conjunctival goblet cells $(0.3 \mu \mathrm{m}$ thick $){ }^{3}$ 


\section{Epithelium}

The corneal epithelium is composed of stratified squamous epithelial cells and makes up $~ 5 \%-10 \%$ of the total corneal thickness. The clarity of the cornea depends partly on the tight packing of epithelial cells to produce a layer with a nearly uniform refractive index and minimal light scattering. ${ }^{1}$ While corneal epithelium acts as a mechanical barrier, the cellular and chemical components of precorneal tear film act as biologic protective systems; therefore, cornea provides a formidable barrier to the invasion by the microorganisms. ${ }^{4}$

\section{Stroma}

The regular arrangement of stromal cells and macromolecules is also necessary for a clear cornea. They are flattened fibroblasts, located between the collagen lamellae. ${ }^{1}$

The cornea contains a much higher percentage of mucopolysaccharides as embedding material for the collagen fibrils than sclera. It has been shown that the regular arrangement of the fibrils is, in fact, the essential factor leading to the transparency of the cornea. ${ }^{5}$

\section{Dua's layer}

Dua's layer is a new layer of the cornea; it is strong, acellular, and well defined after stroma and before Descemet's membrane. Recognition of this layer will provide considerable knowledge about posterior corneal surgery, corneal biomechanics, and posterior corneal pathologies such as acute hydrops, Descematocele, and pre-Descemet's dystrophies. ${ }^{6}$

Transparency also depends on keeping the water content of the corneal stroma at $78 \%$. Corneal hydration is largely controlled by intact, healthy epithelial and endothelial layers and normally functioning endothelial cells pump. ${ }^{1}$

\section{Endothelium}

It is a single-layered, low cuboidal cell. There are $\sim 400,000$ cells of 4-6 $\mu \mathrm{m}$ thickness. These cells are hexagonal in shape and $20 \mu \mathrm{m}$ wide. The number of endothelial cells decreases with age at the rate of $0.3 \%-0.6 \%$ per year. At birth, the cell densities range from 3,500 to 4,000 cells $/ \mathrm{mm}^{2}$, whereas an adult has densities of 1,400-2,500 cells $/ \mathrm{mm}^{2}$. Cornea loses it clarity when the endothelial cell densities reach $400-700$ cells $/ \mathrm{mm}^{2}$ below which corneal edema occurs. $^{2}$

\section{Pachymetry}

Pachymetry refers to the measurement of corneal thickness. ${ }^{7}$ It can used to assess corneal hydration and the corneal endothelial cells function in its dual role as a barrier to aqueous humor and as a metabolic pump. When functioning normally, the endothelial pump balances the leak rate to maintain the corneal stromal water content at $78 \%$ and the central corneal thickness (CCT) at $\sim 540 \mu \mathrm{m}$ that is considered as the normal CCT. ${ }^{1}$

Other factors that affect CCT include corneal biomechanical properties (eg, rigidity), corneal scarring or band keratopathy, corneal irregularity, edema, technician errors in measurement, and measurement done over a soft contact lens. It has been reported that CCT is the most highly heritable aspect of ocular structure. In populations of persons of African ancestry, mean CCT has been found to be lower than that observed in Whites. ${ }^{8}$

The optical zone is the portion of the cornea that overlies the entrance pupil of the iris. The area of maximum curvature typically temporal to the center of the pupil is named corneal apex. The point located at the intersection of the patient's line of fixation and the corneal surface is called the corneal vertex, which is represented by the corneal light reflex when the cornea is illuminated coaxially with fixation. The corneal vertex does not necessarily correspond to the corneal apex.., ${ }^{1,3}$

Measurements of intraocular pressure (IOP) by applanation tonometry are affected by the CCT; hence, measurement with the Goldmann applanation tonometer is most accurate when the CCT is $520 \mu \mathrm{m}$. Increased CCT may give an artificially high IOP measurement (overestimate). Therefore, IOP measured after photorefractive keratectomy and laser in situ keratomileusis (LASIK) may be reduced because of changes in the corneal thickness induced by these and other refractive surgeries. The relation between IOP measurements and CCT is not linear. ${ }^{9}$ Therefore, it is important to remember that any correction factors are only estimates at best. The other factors such as corneal edema or hydration and viscoelasticity probably influence the impact of CCT on IOP measurements. Using a Goldmann applanation tonometer, variations of 4-5 mmHg from true IOP due to CCT were measured. ${ }^{8}$

The Ocular Hypertension Treatment Study showed that CCT is an independent predictive factor for the later development of glaucoma among the patients with ocular hypertension, with increased thinner CCT risk of glaucoma. ${ }^{5}$ Ocular Hypertension Treatment Study found that CCT is a risk factor for progression independent of IOP level. ${ }^{9}$ Therefore, examination of anterior segment of the eye, especially evaluation of CCT and peripheral corneal thickness, is important in various fields of ophthalmology. ${ }^{10}$ Pachymeters employ either optical or ultrasound principles. Optical pachymeters use the PurkinjeSanson images formed by the anterior and posterior surfaces of the cornea (images I and II) to measure corneal thickness and 
the Purkinje-Sanson images formed by the posterior surface of the cornea and the anterior surface of the lens (images II and III) to measure the depth of the anterior chamber. ${ }^{7}$

The pentacam (Oculus Optikgerate GmbH, Wetzlar, Germany) is a newer imaging system that uses a single Scheimpflug camera to measure the radius of curvature of the anterior and posterior corneal surfaces and the corneal thickness for the calculation of corneal power. Another optical device, the Galilei, measures the corneal power by using a dual Scheimpflug camera integrated with a Placido disk. ${ }^{11}$

An ultrasound probe applanates the cornea and only gives a reading when it is perpendicular to the posterior surface. It is invaluable for planning the depth of corneal incisions in graft and refractive surgery.

Until recently, ultrasound pachymetry was the most commonly used clinical method to measure CCT, ${ }^{12}$ and it is widely considered as the gold standard method for the measurement of corneal thickness. ${ }^{13}$ Although the required probe in contact with the cornea is associated with patients' discomfort, the requirement for topical anesthesia, the risk of epithelial lesion (abrasion), and the risk of transmission of infections lead to preference of noncontact methods such as the optical coherence tomography, scanning slit pachymetry, specular microscopy, and corneal confocal microscopy. ${ }^{14}$

Therefore, the measurement of CCT is important in many clinical applications such as glaucoma management, diagnosis of corneal ectatic conditions, corneal physiology, and contact lens researches. ${ }^{10}$

\section{Aim of the study}

To compare the CCT measurements done by ultrasound pachymeter with that done by oculus pentacam in both control group and well-controlled open-angle glaucoma group (when IOP is in normal range for at least two visits).

\section{Patients and methods Study design}

A randomized hospital-based case-control study was carried out during the period from May 2014 till the first of January 2015 at Ibn Al Haitham Teaching Eye Hospital. This study was approved by the Scientific Council of Ophthalmology of Iraqi Board for Medical Specialization. The research follows the tenets of the Declaration of Helsinki, and each patient gave his or her written informed consent to participate in the study.

\section{Study sample}

A total of 173 eyes were collected from Ibn Al Haitham Teaching Eye Hospital during the time of study application.
CCT was measured in 87 eyes of 53 patients with wellcontrolled (when IOP is within normal range for at least two visits) open-angle glaucoma attending Ibn Al Haitham Teaching Eye Hospital, with age range between 25 and 60 years, and another normal 86 eyes of 44 healthy subjects of the same range of ages.

Any eye with corneal pathology as edema, scarring or corneal dystrophy, contact lens wearing history, eyes that underwent refractive or any other type of ocular surgery, and those with a history of ocular trauma of any type and diabetes were excluded from this study. Pregnant ladies were also excluded. In the selection of glaucomatous eyes, patients with a history of angle closure are also excluded.

All measurements were done at the same time of the day (9 am to $12 \mathrm{pm}$ ) few hours after awaking in the comfortable eyes by the same technician. The CCT measurements had been done twice for each eye, first with noncontact oculus pentacam (TYP 70700) and then by ultrasound touch (TOMEY SP_3000) pachymeter without significant time interval. During examination by touch pachymeter, the eyes were anesthetized by instillation of $0.5 \%$ topical Alcaine (proparacaine hydrochloride ophthalmic solution) eye drop once. Results were compared between the two measurements in both control and glaucoma groups.

\section{Data analysis}

Statistical analysis was performed using SPSS Version 20. Categorical variables were presented as percentages and frequencies. Continuous variables were presented as mean \pm standard deviation. Pearson's independent sample $t$-test was used to find the mean difference between two continuous variables. $P$-value of $<0.05$ was considered statistically significant.

\section{Results}

\section{Distribution of study groups according to age}

Figure 1 shows the overall mean age of patients with glaucoma

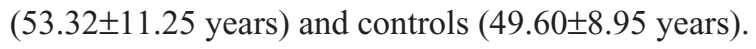

\section{Distribution of study groups according to sex}

Figure 2 shows the distribution of study groups by sex; $62.8 \%$ of the patients with glaucoma were females, whereas $74.4 \%$ of controls were males.

The mean differences of CCT by pentacam and ultrasonic pachymeter among the group of patients with glaucoma and control group are shown in Tables 1 and 2, respectively. 


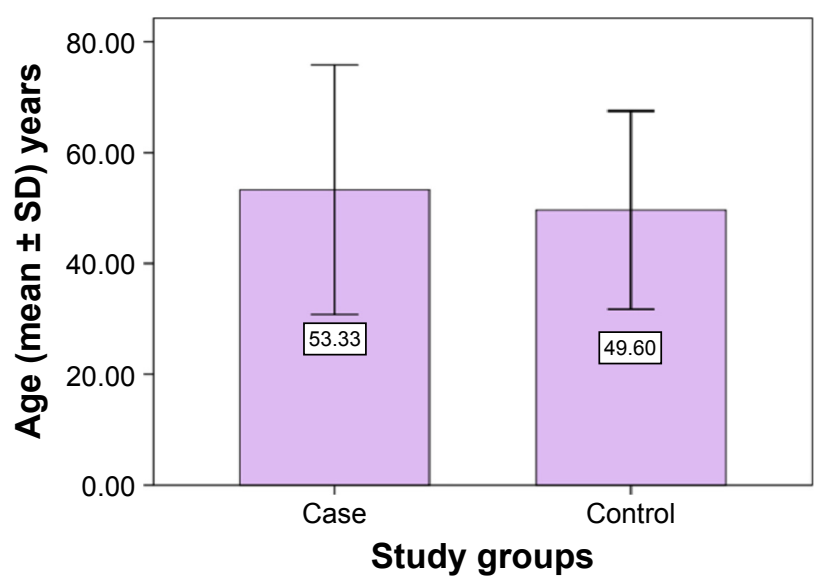

Figure I Distribution of study groups by age. Abbreviation: SD, standard deviation.

As shown from the results of this study, there were no statistically significant differences of CCT readings between the measurements obtained by two devices (oculus pentacam and ultrasound pachymeter) in both control and glaucoma groups.

\section{Discussion}

Pachymetry, or the measurement of the corneal thickness, is an integral part of a thorough ophthalmic evaluation. In refractive surgery, knowledge of the corneal thickness is necessary for choosing the best treatment option and avoiding complications such as corneal ectasia. ${ }^{15}$ Also, CCT determination has become essential in glaucoma patient management. ${ }^{8,16}$

Ultrasound pachymeter measures the CCT by estimating the time difference between echoes of ultrasound waves reflected from the anterior and posterior surface of the cornea. $^{17}$

In ultrasound pachymeter, the definite posterior corneal reflection point is not well known; it could be located between Descemet's membrane and the anterior chamber. It has also

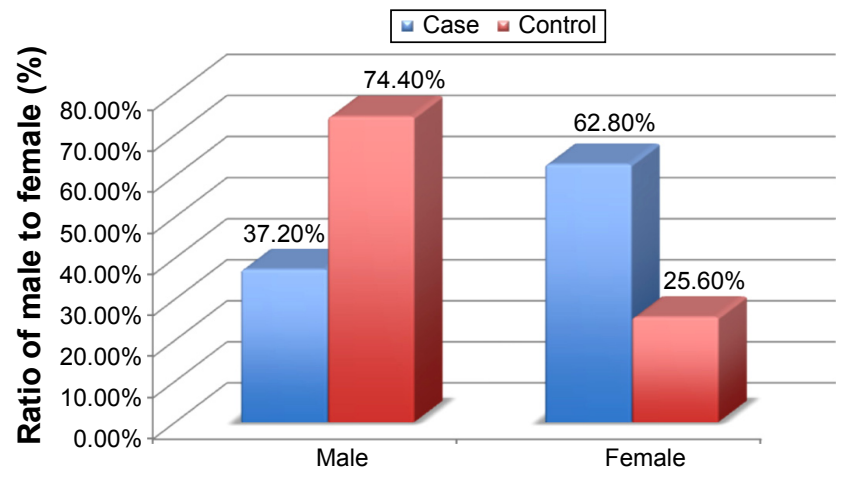

Figure 2 Distribution of study groups by sex.
Table I Mean differences of CCT by pentacam and ultrasound pachymeter among the group of patients with glaucoma

\begin{tabular}{llll}
\hline Test & Mean \pm SD & t-test & $P$-value* \\
\hline CCT by pentacam & $547.29 \pm 49.32 \mu \mathrm{m}$ & 0.048 & 0.96 \\
CCT by UP & $547.66 \pm 45.24 \mu \mathrm{m}$ & & \\
\hline
\end{tabular}

Note: $* P$-value $>0.05$ (statistically not significant).

Abbreviations: CCT, central corneal thickness; SD, standard deviation; UP, ultrasound pachymeter.

been documented that the ultrasonic probe can displace the $7-40 \mu \mathrm{m}$ thickness of the tear film. ${ }^{15}$

The reproducibility of optical devices such as pentacam and Orbscan that depend on measurements of scattered reflected light beams through the corneal tissues might be questionable when the corneal tissue is not clear or has optical interference such as cases of postcorneal surgery. ${ }^{18}$

The results of this study showed no statistically significant differences in CCT readings between the measurements obtained by two devices (oculus pentacam and ultrasound pachymeter) in both control group and patients with glaucoma.

Similar results had been claimed in a study with a sample size of 157 eyes in 2010 by Sedaghat et al who had estimated that CCT measurements using ultrasound pachymetry are relatively the same with scanning slit topography (incorporating a correction factor). Similarly, the pachymetric measurement of central cornea is comparable between rotating Scheimpflug camera and corrected scanning slit topography. ${ }^{19}$ That gives an idea that ultrasound pachymeter and pentacam can be used in a substitutable manner in measuring CCT.

Previously, few studies evaluated CCT using the pentacam and ultrasound pachymeter in eyes that had undergone LASIK. ${ }^{20,21}$ Ciolino et $\mathrm{al}^{20}$ demonstrated that CCT measurements obtained using the pentacam have good correlation and agreement with those obtained using ultrasonic pachymeter; therefore, they suggested that the pentacam can be used as a substitute for ultrasound pachymeter in CCT measurement.

The study done by Amed ${ }^{22}$ in IBSAR center, Al-Najaf city, claimed that the ultrasound pachymeter significantly

Table 2 Mean differences of CCT by pentacam and ultrasound pachymeter among control group

\begin{tabular}{llll}
\hline Test & Mean \pm SD & t-test & P-value* \\
\hline CCT by pentacam & $551.02 \pm 36.28 \mu \mathrm{m}$ & 1.669 & 0.974 \\
CCT by UP & $541.25 \pm 34.96 \mu \mathrm{m}$ & & \\
\hline
\end{tabular}

Note: $* P$-value $>0.05$ (statistically not significant).

Abbreviations: CCT, central corneal thickness; SD, standard deviation; UP, ultrasound pachymeter. 
overestimates the corneal thickness by $\sim 2.85 \mu \mathrm{m}$, and the eyes with refractive errors ranging from $0 \mathrm{D}$ to $-6 \mathrm{D}$ have higher optical CCT values than ultrasonic values, but the differences were not statistically significant. This might be due to small sample size (only 28 patients), frequent use of topical anesthesia for those patients prior to performing refractive surgery, or technician-related differences (accidental probe decentration when using ultrasound pachymeter).

On the other hand, Módis et al when they evaluated three instruments (scanning slit corneal topography, ultrasound pachymeter, and noncontact specular microscopy) had showed that the mean CCT measurement by noncontact specular microscopy was significantly smaller than that obtained by the other two instruments. They also demonstrated that scanning slit topography measurements were higher (statistically significant) than those of the ultrasonic pachymetry; however, this was explained because the acoustic equivalent correction factor was not used by the authors (0.92). Also, scanning slit topography gave 9.6\% higher measurements than ultrasonic pachymetry, but this could have been compensated by the acoustic factor, which decreases the readings by $\sim 8 \% .^{23}$

Two similar studies had reported that similar measurements by ultrasound pachymetry, scanning slit topography, and pachymetry were corrected with the use of acoustic equivalent factor in normal corneas. ${ }^{24,25}$

Despite the high correlation between ultrasound pachymeter and optical CCT measurements, which was concluded in many studies, ${ }^{13,20,24,25}$ Tai et al had showed that the mean CCT measurements by pentacam were $10 \mu \mathrm{m}$ higher than that obtained using ultrasound pachymeter. ${ }^{25}$ Similarly, Hani claimed while measuring CCT in post-LASIK myopic eyes, pentacam device tends to overestimate CCT compared to ultrasound pachymeter, pentacam probably cannot be used interchangeably with ultrasound pachymeter. ${ }^{21,26}$ Recently, Sadoughi et al had compared ultrasound pachymetry and Orbscan II for the measurement of CCT in normal eyes. They found that overall Orbscan II overestimated CCT as compared to ultrasound pachymetry. ${ }^{18}$

All these three results ${ }^{18,21,26}$ could be explained by the fact that the pentacam pachymeter may involve the precorneal tear film in the measurement of corneal thickness, while the probe of ultrasound pachymeter displaces the precorneal tear film and compresses the corneal surface, resulting, therefore, in lower values..$^{19,21}$ Also, a slight tendency for ultrasound methods to underestimate corneal thickness was noted especially if it was carried out prior to optical pachymetry because of the changes in tissue hydration secondary to the ultrasound speed through the cornea. ${ }^{16}$

\section{Conclusion and recommendation}

Our study showed that there was no significant difference in the measurement of CCT obtained by the two instruments, and hence we recommend the use of a nontouch pachymeter in measuring CCT during assessment of patients with glaucoma and various clinical situations in order to reduce the risk of fault in measurement due to technician-related differences, risk of epithelial trauma or infections (corneal touch-related complications), and faults due to epithelial edema from possible frequent use of topical anesthetic agents.

\section{Disclosure}

The authors report no conflicts of interest in this work.

\section{References}

1. American Academy of Ophthalmology. Basic and Clinical Science Course. External Disease and Cornea, Section 8. San Francisco, CA: American Academy of Ophthalmology; 2015:6-39.

2. Sharma N, Vajpayee RB. Corneal Ulcer Diagnosis and Management. Vol. 1. New Delhi: Jaypee Brothers Medical Publishers; 2008:3,5,6.

3. Kanski JJ, Bowling B. Clinical Ophthalmology. Vol. 6. 7th ed. China: Elsevier; 2011:120.

4. Levin LA, Nilsson SFE, Hoeve JV, Wu S, Kaufman PL, Alm A. Adler Physiology of the Eye. 11th ed. Amsterdam: Elsevier; 2011.

5. Rogers K, editor. The Eye, The Physiology of Human Perception. New York, NY: Britannica Educational Publishing; 2011:23,24.

6. Dua HS, Faraj LA, Said DG, Gray T, Lowe J. Human corneal anatomy redefined. AAO J. 2013;120(9):1778-1785.

7. Elkington AR, Frank HJ, Greaney MJ. Clinical Optics. 3rd ed. Hoboken, NJ: Blackwell Science; 1999:207-209.

8. Giaconi JA, Law SK, Coleman AL, Caprioli J, editors. Pearls of Glaucoma Management. Berlin: Springer; 2010:88-90.

9. American Academy of Ophthalmology. Basic and Clinical Science Course, Glaucoma, Section 10. San Francisco, CA: American Academy of Ophthalmology; 2015:24,25,74.

10. González-Méijome JM, Cerviño A, Yebra-Pimentel E, Parafita MA. Central and peripheral corneal thickness measurement with Orbscan II and topographical ultrasound pachymetry. J Cataract Refract Surg. 2003; 29:125-132.

11. American Academy of Ophthalmology. Basic and Clinical Science Course Clinical Optics, Section 3. San Francisco, CA: American Academy of Ophthalmology; 2015:204.

12. De Sanctis U, Missolungi A, Mutani B, Richiardi L, Grignolo FM. Reproducibility and repeatability of central corneal thickness measurement in keratoconus using the rotating Scheimpflug camera and ultrasound pachymetry. Am J Ophthalmol. 2007;144:712-718.

13. Chakrabarti HS, Craig JP, Brahma A, Malik TY, McGhee CN. Comparison of corneal thickness measurements using ultrasound and Orbscan slit-scanning topography in normal and post-LASIK eyes. J Cataract Refract Surg. 2001;27(11):1823-1828.

14. Ramin K, Tanj M, Gerd U. Central and peripheral pachymetry measurements according to age using the Pentacam rotating Scheimpflug camera. J Cataract Refract Surg. 2007;33:830-836.

15. Hashemi H, Mehravaran S. Central corneal thickness measurement with Pentacam, Orbscan II, and ultrasound devices before and after laser refractive surgery for myopia. J Cataract Refract Surg. 2007;33:1701-1707. 
16. Wirbelauer C, Scholz C, Hoerauf H, Pham DT, Laqua H, Birngruber R. Noncontact corneal pachymetry with slit lamp adapted optical coherence tomography. Am J Ophthalmol. 2002;133:444-450.

17. Ling T, Ho A, Holden BA. Method of evaluating ultrasonic pachometers. Am J Optom Physiol Opt. 1986;63:462-466.

18. Sadoughi MM, Einollahi B, Einollahi N, Rezaei J, Roshandel D, Feizi, S. Measurement of central corneal thickness using ultrasound pachymetry and Orbscan II in normal eyes. J Ophthalmic Vis Res. 2015; 10(1):4-9.

19. Sedaghat MR, Daneshvar R, Kargozar A, et al. Comparison of central corneal thickness measurement using ultrasonic pachymetry, rotating Scheimpflug camera, and scanning-slit topography. Am J Ophthalmol. 2010;150:780-789.

20. Ciolino JB, Khachikian SS, Belin MW. Comparison of corneal thickness measurements by ultrasound and Scheimpflug photography in eyes that have undergone laser in situ keratomileusis. Am J Ophthalmol. 2008; 145:75-80.

21. Al-Mezaine HS, Al-Amro SA, Kangave D, Al-Obeidan S, Al-Jubair KM. Comparison of central corneal thickness measurements using Pentacam and ultrasonic pachymetry in post-LASIK eyes for myopia. Eur J Ophthal. 2010;20(5):852-857.
22. Amed HM. Corneal thickness measurement with optical and ultrasonic pachymetry. Med J Babylon. 2012;9(4):772-776.

23. Módis L Jr, Langenbucher A, Seitz B. Scanning-slit and specular microscopic pachymetry in comparison with ultrasonic determination of corneal thickness. J Cornea. 2001;20:711-714.

24. Fakhry MA, Artola A, Belda JI, Ayala MJ, Alió JL. Comparison of corneal pachymetry using ultrasound and Orbscan II. J Cataract Refract Surg. 2002;28:248-252.

25. Tai LY, Khaw KT, Ng CM, Subrayan V. Central corneal thickness measurements with different imaging devices and ultrasound pachymetry. J Cornea. 2013;32:766-771.

26. Barkana Y, Gerber Y, Elbaz U. Central corneal thickness measurement with the Pentacam Scheimpflug system, optical low-coherence reflectometry pachymeter and ultrasound pachymeter. J Cataract Refract Surg. 2005;31:1729-1735.
Clinical Ophthalmology

\section{Publish your work in this journal}

Clinical Ophthalmology is an international, peer-reviewed journal covering all subspecialties within ophthalmology. Key topics include: Optometry; Visual science; Pharmacology and drug therapy in eye diseases; Basic Sciences; Primary and Secondary eye care; Patient Safety and Quality of Care Improvements. This journal is indexed on

\section{Dovepress}

PubMed Central and CAS, and is the official journal of The Society of Clinical Ophthalmology (SCO). The manuscript management system is completely online and includes a very quick and fair peer-review system, which is all easy to use. Visit http://www.dovepress.com/ testimonials.php to read real quotes from published authors. 